\title{
Por que o Tractatus necessita de um sujeito transcendental?
}

\author{
João Vergílio G. Cuter \\ Universidade de São Paulo
}

resumo Há razões de ordem estritamente lógica para que Wittgenstein tenha postulado no Tractatus a existência de um sujeito transcendental. Sem esse sujeito, o Tractatus não teria como lidar com a constituição do sentido proposicional. É ele o responsável pela associação entre nomes e objetos e pela efetuação de operações lógicas como a negação, a quantificação e a atribuição numérica.

palavras-chave Wittgenstein - lógica - sujeito transcendental - linguagem - sentido proposição.

Este texto ${ }^{1}$ pretende fazer basicamente duas coisas. Em primeiro lugar, ele tentará responder à questão que o intitula, dando ênfase ao verbo "necessitar". Quero saber o que faz com que a postulação de um sujeito transcendental postado nos limites do mundo seja uma absoluta necessidade. Quero saber, enfim, por que o Tractatus não pode - se é que não pode, mesmo - passar sem ele. Minha resposta, aqui, amplia e aprofunda uma solução que propus a esse problema em outros textos (CUTER, 1999, 2004). Basicamente, procurarei mostrar que o sujeito transcendental deve ser entendido como uma vontade que nomeia e que opera: uma vontade que estabelece as conexões entre linguagem e mundo e que constrói proposições a partir de proposições já dadas. Minha tese é que, sem esse sujeito, nenhuma proposição elementar poderia ser projetada sobre uma situação possível, e nenhuma proposição molecular poderia ser construída a partir das proposições elementares. Sem ele, a linguagem, tal como o

Recebido em 15 de dezembro de 2005. Aceito em 12 de março de 2006.

doispontos, Curitiba, São Carlos, vol. 3, n. 1, p.171-192, abril, 2006 
Tractatus a concebe, não poderia articular pensamentos, e é exatamente por isso que esse sujeito deve ser visto, não como um apêndice mais ou menos desarticulado do restante do livro, mas como um pressuposto absolutamente indispensável à constituição do sentido.

\section{I}

Não é raro encontrarmos comentadores de primeira linha que tentam associar o tema do sujeito transcendental no Tractatus a este ou aquele capítulo da história da filosofia. Não há nada de errado em aproximações deste tipo. No caso de Schopenhauer, por exemplo, é inquestionável que Wittgenstein leu atentamente O Mundo como Vontade e Representação, e ficou profundamente impressionado. Há boas razões também para admitirmos que ele foi "influenciado" por essa obra. Há temas e termos que são transpostos para o Tractatus de maneira quase citacional, indicando claramente uma espécie de dívida reconhecida pelo próprio autor. No entanto, esta talvez seja uma boa ocasião para recordar a distinção (tão cara ao Wittgenstein da maturidade) entre causas e razões.

Uma "influência" é, antes de tudo, uma relação causal inscrita na evolução intelectual de alguém. Coisas ditas por uma pessoa marcam uma outra de tal maneira que esta última as incorpora à sua própria maneira de pensar e ao seu próprio modo de ver o mundo. Em determinados casos, a influência é tão grande que a pessoa que a sofre transforma-se num epígono, num repetidor, ou, nos piores casos, num plagiário. Nestes casos, o melhor talvez seja ir diretamente à fonte. As razões de um repetidor estão escondidas na obra repetida. É lá mesmo que elas devem ser procuradas.

Nem sempre se trata, é bom lembrar, de um caso de falta de talento ou, pior, de um caso de polícia. Na ciência, este tipo de repetição acontece com freqüência no contexto daquilo que Kuhn denominava "ciência normal". Todos aqueles que se dedicam a desenvolver um paradigma são, num certo sentido, epígonos dos autores mais centrais. As repetições, devidamente citadas, não marcam, neste caso, uma "influência" exercida na obra de cada cientista. Elas não estão ali simplesmente para sinalizar uma dívida. Elas sinalizam razões, e não necessariamente causas. Elas justi- 
ficam de maneira abreviada aquilo que se diz. $\mathrm{Na}$ filosofia, muitas vezes temos relações deste tipo. Há autores que estão simplesmente desenvolvendo o sistema filosófico de outros, a ponto de a sua filosofia não se distinguir claramente da que lhe serve de base e de guia. A menção de uma certa passagem, ou de uma certa tese, nestes casos, carrega consigo todo o contexto argumentativo original. As razões do epígono, salvo menção explícita em contrário, são as razões de seu mestre. Temos boas razões, aqui, para entender aquilo que é dito na obra menor à luz daquilo que foi dito na obra principal. A articulação lógica entre ambas não precisa ser postulada, pois é constitutiva do movimento interno do texto.

Não é isto o que encontramos no Tractatus. Não é esse o lugar de que Wittgenstein está falando - o lugar do epígono servil, que repete as doutrinas do mestre para melhor desenvolvê-las. O Tractatus é um livro que busca estabelecer as condições de possibilidade do discurso em geral - as condições de possibilidade daquilo que Frege chamava de "pensamento". Ele está inteiramente assentado na constatação da necessidade de uma relação de isomorfismo entre a linguagem e o mundo, ou, mais exatamente, entre a linguagem e aquilo que Wittgenstein chama de "substância do mundo" - a totalidade dos objetos logicamente simples, cujas possibilidades e impossibilidades combinatórias espelham a sintaxe lógica de toda e qualquer linguagem possível. É a partir desta base que todo o edifício do Tractatus se constrói. No final das contas, a justificativa última para tudo o que Wittgenstein diz ali é sempre a mesma: "isto tem que ser assim, pois, de outro modo, o sentido não tem como se constituir".

É uma interpretação deste tipo que estou procurando aqui para os aforismos do Tractatus que se referem a esse sujeito "que não pertence ao mundo, mas é um limite do mundo" (5.632). O mundo de Wittgenstein não é o mundo de Schopenhauer, nem de nenhum outro filósofo. É a totalidade dos estados de coisas que subsistem, totalidade esta definida em termos de um espaço lógico de possibilidades de combinação de objetos logicamente simples. Ser um limite do mundo significa, por um lado, estar excluído dessa rede de possibilidades combinatórias e, por outro, estar essencialmente vinculado a ela por alguma razão que cabe ao intérprete revelar. Se este sujeito tem que estar sozinho, se não pode haver nenhum outro sujeito postado ali, nos confins do sentido, deve haver razões lógicas precisas para isto, e não apenas motivos ligados à 
formação filosófica de Wittgenstein. Nem mesmo o esclarecimento da natureza desse sujeito, concebida à parte das funções lógicas que ele é chamado a desempenhar, pode ser adequadamente determinada por analogia com outras filosofias que nada têm a ver com a dele. No máximo, tais analogias poderiam ilustrar e dar um colorido biográfico peculiar a uma leitura estruturada em torno de um eixo fixado no próprio Tractatus, e não alhures.

Tentarei mostrar que o sujeito transcendental tractariano, longe de ser um capricho imotivado, ou um acidente biográfico filosoficamente irrelevante, é uma necessidade lógica. Tentarei mostrar que ele é "transcendental" nos dois sentidos mais importantes da palavra: em primeiro lugar, porque é uma condição absoluta de possibilidade de um certo âmbito; em segundo lugar, porque está absolutamente excluído desse mesmo âmbito. ${ }^{2} \mathrm{O}$ âmbito, no caso, é o do sentido. Sendo assim, para mostrar que o sujeito é transcendental, terei que mostrar, antes de tudo, que, sem a sua intervenção, o sentido proposicional não tem como se constituir. O segundo sentido da transcendentalidade será, então, decorrência imediata do primeiro: o que é condição de possibilidade do sentido não pode ser dito, mas deve mostrar-se de algum modo no próprio emprego de sinais significativos.

Uma vez determinada esta dupla transcendentalidade do sujeito tractariano, ficará fácil demonstrar que esse sujeito deve ser o portador de uma vontade sui generis, dirigida, não ao mundo, mas à substância do mundo. Trata-se de uma vontade que nada tem de fatual, uma vontade a respeito da qual, portanto, a psicologia nada teria a dizer. Neste ponto, seremos capazes de compreender por que o sujeito instaurador do sentido é também o sujeito portador do ético, do valor absoluto que está fora da história, pois está fora do mundo, e que nada tem a ver, por isso, com a economia mundana dos crimes e castigos.

Muito embora a palavra "intencionalidade" não apareça no Tractatus, a idéia está por toda a parte. Wittgenstein optou por introduzir o conceito por meio de uma nomenclatura estranha, posto que útil para vinculá-lo 
ao contexto mais amplo da teoria da figuração. A ligação entre nome e objeto, a projeção daquilo que, no pensamento, nomeia sobre aquilo que, no mundo, é nomeado, atende, no Tractatus, pelo nome de "relação afigurante" [abbildende Beziehung]. Esta relação é formalmente definida em termos das "coordenações entre os elementos da figuração e as coisas" (2.1514), e mais pitorescamente descrita como um conjunto de "antenas" com as quais a figuração, à maneira de um inseto, entra em contato com o mundo (2.1515). Podemos pensá-la como aquela relação por meio da qual um nome (no rigoroso sentido lógico do termo) adquire significado ao ser associado a um objeto logicamente simples.

A primeira coisa que eu gostaria de assinalar é que esta relação deve ser dotada de uma assimetria essencial: é o nome que deve designar o objeto, e não o contrário. A relação deve "ir", digamos assim, da linguagem para o mundo, da mesma forma que a antena deve ir do inseto para o mundo. A relação afigurante deve estar investida desse "direcionamento" que associamos às diversas formas de intencionalidade.

Mas este direcionamento ainda não é suficiente. Uma relação afigurante estabelece uma ligação entre nome e objeto capaz de dotar o nome de um significado. Ela é instituidora do significado do nome. Sem ela, nada seria nome de coisa alguma. Numa palavra, devemos contar as relações afigurantes entre as condições de possibilidade do sentido e, nessa medida, devemos contá-la entre as coisas que não podem ser ditas, mas apenas mostradas. Ela não é um fato. Deve subsistir, para que os sinais da linguagem possam dirigir-se ao mundo, mas exatamente por isso não pode ser parte daquilo que a linguagem é capaz de descrever. Como toda condição de possibilidade do sentido, relações afigurantes são inefáveis. São antenas lançadas sobre o mundo, mas que estão fora dele. São aquilo que o Tractatus chama de "relações internas".

O caráter inefável dessas relações pode ser facilmente mostrado de maneira mais direta por meio de uma espécie de redução ao absurdo. Suponhamos que " $A$ " seja o nome de um objeto, e suponhamos que queiramos descrever essa relação afigurante por meio de uma proposição. A única alternativa seria construir uma proposição do tipo " $A$ ' é nome de $A$ ". É claro, em primeiro lugar, que o nome " $A$ " ocorre uma única vez nesta suposta proposição: no final dela. No começo, o que temos é um nome do nome do objeto $A$. Se tivéssemos aqui uma proposição 
genuína, descrevendo uma situação possível no espaço lógico, ela deveria poder ser falsa, e é claro que, se ela fosse falsa, não deveria ter o sentido que gostaríamos que ela tivesse, já que, nesse caso, o último símbolo que usamos - o nome " $A$ " - não designaria o objeto $A$, e a proposição como um todo não estaria dizendo aquilo que pretendemos que ela diga - que o nome " $A$ " designa o objeto $A$. Estaria dizendo uma outra coisa, ou coisa nenhuma. Ou seja, se supusermos que a relação entre um nome e um objeto pode ser descrita, qualquer proposição que se apresente como candidata à tarefa descritiva deve ser, antes de tudo, verdadeira para poder ter o sentido que tem. No entanto, uma sentença só é verdadeira (ou falsa, conforme o caso), porque tem o sentido que tem, e não o contrário. Fazer com que o sentido de uma sentença pressuponha sua verdade é colocar o carro da lógica antes de seus bois, e isto é um erro que Wittgenstein não se cansava de denunciar.

Falando de modo aproximado, podemos dizer qual é a cor de um objeto, mas não podemos dizer qual é o seu nome. Podemos, isto sim, usar o nome que ele tem para descrever coisas como a sua cor, a sua posição em relação a outros, e assim por diante. Ao usar o nome nestes contextos, a nomeação se mostra. Na terminologia do Tractatus, o que está sendo mostrado é exatamente aquela relação afigurante que projeta um elemento da linguagem num objeto constituinte da substância do mundo.

Relações afigurantes, portanto, devem ter essa assimetria essencial que faz com que elas se dirijam da linguagem para o mundo, e devem também ser inefáveis, isto é, devem estar fora do mundo. Existe, no entanto, uma outra característica das relações afigurantes que, embora não seja explicitamente tematizada no Tractatus, é absolutamente essencial para que a nomeação possa acontecer. Relações afigurantes não são inerentes a nenhum fato ou objeto. Nada é, por sua própria natureza, nome de coisa alguma. A nomeação é uma relação interna que deve ser instituída.

Um modo de tornar mais evidente esta relativa autonomia do nome em relação ao objeto nomeado é imaginar que tenhamos chegado ao final do processo de análise. Nesta situação, diante da rede de possibilidades revelada pela análise, consideremos dois nomes - " $A$ " e " $B$ " pertencentes à mesma categoria lógica, isto é, que tenham as mesmas possibilidades de combinação sintática. A ambos devem estar associados, segundo Wittgenstein, dois objetos - $A$ e $B$ - que pertencem à mesma 
categoria ontológica, isto é, que possuem a mesma forma, no sentido do aforismo 2.041.

É claro que poderíamos conceber uma linguagem que fosse exatamente igual a essa, mas na qual certas relações afigurantes fossem permutadas. Faríamos, por exemplo, o nome " $A$ " designar o objeto $B$, e o nome " $B$ " designar o objeto $A$. Nada seria perdido com isso. O poder expressivo da linguagem continuaria exatamente igual, e o mundo continuaria sendo exatamente aquilo que é. Isto significa que a vinculação do nome " $A$ " ao objeto $A$ não é, de forma alguma, uma condição de possibilidade do sentido. Ela é, num sentido importante, indiferente. O importante é que algum nome seja vinculado ao objeto $A$, que um outro nome seja vinculado ao objeto $B$, e que estes dois nomes estejam inseridos na mesma categoria sintática. A natureza dos nomes é neutra com respeito à escolha do objeto específico que o nome deve nomear; ela só não é neutra com respeito à escolha da forma desse objeto, isto é, da categoria ontológica em que ele está inserido.

Um outro modo de dizer a mesma coisa é afirmar que a nomeação está subdeterminada pelos objetos nomeados. A nomeação só se completa mediante um ato que determina algo que não está determinado pela condição de isomorfismo: o ato de vincular este nome àquele objeto. Antes desse ato, só podíamos garantir que tal e tal nome poderia vincular-se a um objeto de tal e tal categoria, a saber, a categoria ontologicamente isomorfa à categoria sintática em que o nome está inserido. Não estava determinado ainda, porém, a qual objeto dessa categoria aquele nome viria a ser vinculado. De um ponto de vista lógico, a vinculação é uma determinação superveniente. Ela não está dada. Ela tem que ser feita. É esse, me parece, o sentido profundo do aforismo 2.1: "Fazemos figurações de fatos". A figuração é produto de uma ação, ela é instituída, ela não está inscrita no fato que utilizamos para representar um fato possível. Só uma projeção pode fazer com que um fato semanticamente neutro se transforme numa figura. A projeção não é um fato, nem pertence ao fato. Ela é adventícia. As relações afigurantes, que realizam esta projeção, pertencem à figuração, mas não ao fato que é transformado em figuração pela atividade projetiva.

$\mathrm{Na}$ base de toda figuração, portanto, tem que existir aquilo que poderíamos chamar de um ato doador de sentido: um ato que institui a 
relação afigurante entre nome e objeto. Não se trata, porém, como já vimos, de uma instituição usual, no interior do mundo. $\mathrm{O}$ ato e aquilo que ele realiza fazem parte das condições de possibilidade do sentido, e não podem, por isso, fazer parte do mundo. Nem o ato, nem a relação por ele instituída podem ser descritos. Eles se deixam mostrar no exercício da linguagem. Esse ato, portador de uma assimetria essencial que visa um elemento de um fato como nome de um objeto, pode perfeitamente ser descrito como uma intencionalidade atuando fora do mundo, fazendo uma espécie muito particular de escolha: o que será nome de que. Essa intencionalidade apresenta-se, portanto, como o ato de um sujeito - um ato que, como procurei mostrar, não é um capricho teórico, mas algo que, para o Wittgenstein do Tractatus, acabou se revelando absolutamente necessário à constituição do sentido.

Eis aqui a primeira razão tractariana para a aceitação de um sujeito transcendental: sem um sujeito posto nos limites do mundo, não seria possível transformar fatos em figuras, pois não seria possível transformar componentes de fatos em nomes. O sujeito tractariano é, antes de tudo, o sujeito da nomeação. A relação entre nome e objeto, instituída por esse sujeito, é interna e, nesta medida, é logicamente necessária. O fato usado como figura não se altera enquanto fato. Nada se passa com ele no interior do mundo. Lançando mão de uma comparação grosseira, mas bastante viva, podemos dizer que nem uma única molécula de um desenho se altera pelo fato de ele representar esta situação, e não aquela outra. A alteração se dá, digamos assim, no estatuto lógico do fato. Ocorre aqui algo semelhante àquilo que os católicos chamam de "transubstanciação": ao transformar-se em figura, o fato conserva todas as suas propriedades externas, mas ganha propriedades internas. Quem faz essa passagem deve ser o sujeito de uma ação, mas não pode estar no interior do mundo. Devemos postular, por isso, um sujeito postado nos limites do mundo: nos limites daquilo que pode ser dito.

\section{III}

Mas não é só para nomear que o sujeito transcendental mostra-se indispensável. Ele também é necessário para operar. Uma operação, segundo o 
Tractatus, é "aquilo que deve acontecer a uma proposição para que, a partir dela, uma outra seja feita" (5.23, grifos meus).

Operações de verdade constituem o primeiro tipo a ser considerado. O que caracteriza este tipo de operação é, como o nome já diz, uma relação funcional entre os valores de verdade da proposição (ou, conforme o caso, das proposições) de que se parte e o valor de verdade da proposição a que se chega. Dado o valor de verdade das proposições da base, deve estar dado também o valor de verdade da proposição obtida pela aplicação da operação de verdade a essa base. A negação simples fornece um caso paradigmático. Se partimos de uma proposição verdadeira, chegamos a uma proposição falsa, e, se partimos de uma falsa, chegamos a uma verdadeira.

Para que possamos dizer que uma operação qualquer é lógica, ela deve estar assentada sobre uma relação formal entre base e resultado. Esta relação não se esgota, é claro, na relação "geométrica", digamos assim, existente entre o sinal da proposição de base e o sinal da proposição resultante. Negar não é escrever um til à esquerda de um padrão gráfico estampado num papel. O que acontece sobre a superfície do papel é uma operação tipográfica tão descritível quanto a elaboração de um padrão geométrico usual, como uma linha grega, ou uma espiral. Quem nega opera sobre o sentido da proposição, invertendo-o. É essa inversão de sentido que constitui a operação lógica cuja ocorrência podemos assinalar por meio de uma operação tipográfica convencionalmente eleita.É essa inversão que chamamos de "negação".

Ora, a inversão de um sentido é claramente algo que não pode ser descrito, que pertence às condições de possibilidade da representação, e que está, por isso, aquém do espaço daquilo que pode ser representado. Qualquer descrição que fizéssemos já estaria inserida no espaço da bipolaridade: ela poderia ser verdadeira ou falsa. A possibilidade de uma proposição ser falsa determina a inclusão, no campo do sentido, de sua negação: deve fazer sentido - e, por isso, deve ser possivvel dizer que o fato descrito pela proposição não acontece. A descrição não é feita de um lugar do qual pudéssemos divisar a negação como uma possibilidade a ser descrita; ela é feita de um lugar no qual a negação já deve estar dada. A inversão do sentido não é um fato. Ela é algo que deve "acontecer" (geschehen, cf. 5.23) ao sentido de uma 
proposição, para que, a partir dela, uma outra proposição possa ser "feita", possa ser "construída".

Mais uma vez, porém, não devemos pensar aqui num acontecimento mundano, inserido na oposição entre o verdadeiro e o falso. Inverter o sentido de uma proposição não é de maneira alguma comparável a virar uma roupa no avesso. Trata-se de um acontecimento inefável, cuja possibilidade é constitutiva desse espaço bipolar em que o sentido se articula. A negação é algo que deve poder ser feito, mas que não pode ser feito no interior dos limites lógicos do mundo. Como toda ação, a negação demanda um sujeito que aja - no caso, um sujeito que negue, que leve a cabo a inversão do sentido. Este sujeito, porém, não pode ser um fato, nem um elemento constitutivo dos fatos. Ele deve ser transcendental, e deve agir a partir de um posto localizado nos limites do sentido.

\section{IV}

As operações lógicas supõem um outro tipo de atividade transcendental que passa despercebida no caso da negação simples, mas que salta aos olhos no caso da negação simultânea. Refiro-me à atividade de selecionar as proposições sobre as quais uma operação irá aplicar-se. A negação simultânea, tal como definida no Tractatus, é uma operação sem "aridade" definida. Ela supõe que um conjunto de proposições tenha sido selecionado e que uma variável proposicional possa percorrer cada uma das proposições do conjunto. Na notação proposta por Wittgenstein, essa variável proposicional é representada por aquilo que é chamado, no Tractatus, de "expressão parentética" (Klammerausdruck). Em 5.501, Wittgenstein lista os três métodos que podem ser utilizados para selecionar proposições abrangidas por uma "expressão parentética". Vale a pena examiná-los separadamente, para compreendermos melhor a natureza de duas outras tarefas lógicas que o sujeito transcendental será chamado a executar.

O método mais simples é o da enumeração tout court. Neste caso, eu simplesmente reúno as proposições numa "lista", e associo uma expressão parentética a essa lista. Deste modo, se $p, q$ e $r$ forem três proposições diferentes, posso associar a elas a variável “ $\xi$ ”, que dará origem à expressão 
parentética “( $\xi$ )", que representa a totalidade dos valores percorridos pela variável (isto é, $p, q$ e $r$ ). Posso, agora, usar este grupo de proposições selecionadas por enumeração direta como base para a aplicação de uma operação de verdade, como a negação simultânea. O resultado é uma proposição que só é verdadeira caso $p, q$ e $r$ sejam todas falsas. Aqui, como no caso da negação simples, o que está sendo submetido a uma operação é o sentido das proposições coletadas sob a variável " $\xi$ ”. A operação incide sobre o sentido, e tanto o material que ela transforma quanto o resultado a que ela conduz pertencem ao reino do que, só podendo ser mostrado, está desde logo excluído do reino dos fatos. A negação simultânea, porém, só pode aplicar-se a um grupo de sentidos proposicionais reunidos de antemão, e a reunião de sentidos é obviamente tão pouco dizível quanto a operação que a sucede. Da mesma forma que a negação, a reunião dos sentidos também só pode ser feita por meio de um ato inefável de um sujeito transcendental.

É óbvio que o número de sentidos colecionados é irrelevante. Mesmo na seleção de um único sentido, sobre o qual aplicaremos uma negação simples, o sujeito transcendental está pressuposto. Não há como negar uma única proposição sem antes visá-la como alvo da operação lógica de inversão do sentido. A intencionalidade que visa o sentido a ser negado é a mesma que o constituiu a partir das formações elementares, por meio de relações afigurantes. A reunião de sentidos, como a nomeação, só pode ser efetuada mediante a atividade de um sujeito subtraído à contingência do mundo.

O mesmo pode ser dito a respeito de grupamentos mais complexos, envolvendo, não um, nem dois, nem três sentidos, mas uma infinidade deles. Aqui, fica ainda mais clara a exigência de uma intencionalidade que selecione proposições sobre as quais essa mesma intencionalidade terá que operar. O mecanismo de quantificação depende essencialmente de seleções desse tipo, nas quais estão envolvidos todos os valores de uma certa função proposicional. Para tornar as coisas mais simples, imaginemos uma proposição elementar qualquer. Ela será, como toda proposição elementar, uma concatenação imediata de nomes. Se considerarmos qualquer um desses nomes, sempre haverá uma classe de nomes que podem ocupar o lugar do primeiro. Bastará, aqui, considerar a totalidade dos nomes pertencentes à mesma categoria lógica do nome de que 
partimos. Essa totalidade é logicamente determinada. Ela é determinada, na verdade, pela forma lógica do objeto nomeado e pela correspondente categoria sintática do nome. Essa totalidade pode ser finita ou infinita, não importa. Como ela pertence às condições de possibilidade do sentido lingüístico, ela se mostra. Tanto quanto a negação, ou a nomeação, a ordem categorial comum ao mundo e à linguagem não pode ser descrita por nenhum tipo de proposição ou teoria. Esse fora, afinal, um dos erros que, desde o início, Wittgenstein associava à teoria dos tipos de Russell. Como poderíamos pretender articular um discurso que descrevesse a ordem categorial do mundo espelhada na linguagem, se, ao articular tal discurso, essa ordem já deveria estar sendo respeitada? Como acomodar a possibilidade de ser falso um discurso que, se fosse mesmo falso, seria, antes de tudo, carente de sentido?

Dadas as categorias em que se distribuem os nomes da linguagem, a quantificação pode ser feita sem maiores problemas. Suponhamos, por um momento, que "João está nesta sala" seja uma proposição elementar produzida pela concatenação imediata dos nomes "João" e "está nesta sala"; suponhamos ainda que a categoria ontológica a que João pertence seja composta por um número infinito de objetos. Isto determina uma classe também infinita de proposições que obtemos quando substituímos o nome "João" pelos diversos nomes de objetos pertencentes a essa categoria: "Luiz está nesta sala", "Paulo está nesta sala", e assim por diante. A função proposicional " $\mathrm{x}$ está nesta sala" percorre, portanto, um número infinito de sentidos proposicionais possíveis. Apesar dessa infinitude, a totalidade destes sentidos está formalmente determinada, e pode ser visada para a aplicação de uma operação lógica qualquer, como a negação simultânea. De fato, a negação simultânea de todas as infinitas proposições assim reunidas produziria o sentido correspondente à sentença "Não há ninguém nesta sala". Selecionando esta proposição e negando-a, chegamos à proposição "Há pelo menos uma pessoa nesta sala".

Mecanismos análogos nos permitem construir as proposições "Há pelo menos duas pessoas nesta sala", "Há pelo menos três...," "Há exatamente uma...", "Há exatamente duas...", e assim por diante. Consideremos, então, a seguinte série de proposições

"Não há ninguém nesta sala",

"Há exatamente uma pessoa nesta sala", 
"Há exatamente duas...",

"Há exatamente três...", etc.

Dadas nesta ordem, estas proposições formam o que Wittgenstein chama de uma "série formal", ou "série de formas" [Formenreihe]. Ao contrário dos valores de uma função proposicional, os valores de uma série formal não são dados em bloco, mas sim por meio de um procedimento recursivo de produção de proposições a partir de outras. Falando de modo aproximado, diríamos que há um número fixo de operações lógicas sendo realizadas de modo regular quando passamos de um ponto na série para o ponto seguinte. O mecanismo formal envolvido é relativamente simples, e não nos interessa aqui. Importa apenas dizer que a série das infinitas proposições que podemos construir assim é, também ela, uma totalidade formalmente determinada. Também ela determina um mecanismo de seleção tão legítimo quanto o que envolve a enumeração direta das proposições, ou quanto o que se vale da categoria de um dos nomes para determinar uma classe de proposições formalmente aparentadas. Se negarmos simultaneamente as proposições da série formal mencionada acima, estaremos dizendo que há infinitas pessoas nesta sala: estaremos dizendo que é falso que a sala esteja vazia, mas que também é falso que exista nela um número determinado de pessoas. Dizer isto é dizer que há infinitas pessoas nesta sala.

Como vemos, o Tractatus não tem problema nenhum em fazer referência a um número infinito de objetos (em nosso exemplo, seres humanos) que possuem esta ou aquela propriedade (em nosso exemplo, estar nesta sala). Tudo que Wittgenstein exige é que as totalidades sejam formalmente determinadas, isto é, que haja algum traço ou mecanismo formal reunindo as infinitas proposições da série. A lógica, para Wittgenstein, não joga dados. Toda e qualquer totalidade admitida no reino do sentido deve estar logicamente circunscrita. Estando logicamente circunscrita, faz pouca diferença se essa totalidade é finita ou infinita. Ela estará disponível para a aplicação das operações verifuncionais por meio das quais obtemos proposições mais complexas a partir de proposições mais simples. Tanto quem faz a seleção quanto quem aplica as operações é, aqui como antes, um sujeito de ações a um só tempo necessárias e indescritíveis. Sem ele, não há nomes, nem proposições elementares, nem 
negação ou quantificação, nem especificações numéricas. A lógica é transcendental, e o sujeito da lógica também tem que sê-lo.

Existem, portanto, três boas razões lógicas para Wittgenstein postular um sujeito fora do mundo, inacessível a toda e qualquer descrição. Se não postulasse tal sujeito, Wittgenstein jamais poderia ter falado a respeito de nomes, operações lógicas e seleções lógicas do modo que falou. Em todos estes casos, um agente metafísico precisa ser pressuposto por trás das tarefas lógicas que devem ser realizadas. Muito embora Wittgenstein não fale nestes termos, é perfeitamente apropriado pensar neste sujeito como uma intencionalidade pura que projeta nomes sobre o mundo, inverte o sentido das proposições e dirige uma atenção não empírica a certos grupos formalmente determinados de sentidos proposicionais sobre os quais irá atuar operacionalmente, produzindo novas proposições a partir das que foram selecionadas.

Em termos mais abstratos, essa intencionalidade pura pode ser pensada como uma vontade não-empírica, pois ela está encarregada de fazer escothas logicamente necessárias à constituição do sentido - a escolha de o que é nome de quê, a escolha entre afirmar e negar, a escolha de um grupo (finito ou infinito) de sentidos, e a escolha daquilo que deve ser feito com o grupo de sentidos assim reunido. Numa palavra, essa intencionalidade se apresenta como uma vontade de significar. Não se trata, como é fácil constatar, de uma vontade empírica direcionada ao mundo, dessas que vão à geladeira e pegam um pouco de sorvete; trata-se, aqui, de uma vontade transcendental aplicando-se ao reino atemporal dos objetos e das relações lógicas entre proposições. É uma vontade transitando no âmbito atemporal da lógica, onde se constituem os sentidos, e onde nenhum sentido pode, por isso mesmo, penetrar.

\section{V}

Este contato místico com a eternidade está inevitavelmente presente na formação de qualquer sentido, mas apenas de um modo, por assim dizer, "instrumental". Quando falo, devo direcionar minha intencionalidade transcendental para o reino dos objetos e das relações lógicas, objetivando a produção de sentidos. Penso que, neste ponto, Wittgenstein divisou 
uma outra possibilidade, e que toda a parte final de seu livro, longe de ser uma espécie de plágio de alto padrão, é, na verdade, um longo e belíssimo desenvolvimento dessa possibilidade que tem suas raízes na teoria tractariana do sentido.

Essa doutrina deixa em aberto a possibilidade de que o sujeito transcendental projete suas "antenas" intencionais na eternidade tendo em vista, não a produção de sentidos, mas a própria eternidade. De fato, parece haver duas espécies possíveis de passagem pelo reino atemporal dos objetos. A primeira, já vimos, é de natureza instrumental, feita a serviço de uma racionalidade tagarela e distraída, permanentemente empenhada na construção de sentidos e na comparação dos sentidos que ela constrói com aquilo que, de fato, ocorre. Pondo o foco nas proposições tomadas isoladamente, e nos fatos com as quais devemos compará-las, esta racionalidade está sempre mergulhada numa porção do mundo e da linguagem, perguntando-se pelas concatenações em que este ou aquele objeto, como questão de fato, ocorre, ou não. Ela procura acumular verdades em número cada vez maior, e não busca tanto penetrar na realidade, mas sim percorrê-la do começo ao fim. É disto que falamos até aqui.

Suponhamos, porém, que esse mesmo direcionamento aos objetos não esteja a serviço da produção do sentido. $O$ sujeito não visaria o objeto para uni-lo a um nome, mas simplesmente para contemplar o espaço lógico. Não mostraria mais interesse por tal concatenação de objetos do que por tal outra. Uma proposição verdadeira não teria, para ele, mais valor do que uma falsa, simplesmente porque não estaria visando o domínio das verdades, mas sim o domínio do sentido. O mundo, deste ponto de vista, seria simplesmente um dos infinitos recortes possíveis do espaço lógico, e o interesse recairia sobre ele como um todo, e não sobre esta ou aquela de suas partes. $\mathrm{O}$ mundo seria visto - contemplado - contra o pano de fundo da eternidade, do ponto de vista da eternidade, subsumido a ela. $\mathrm{O}$ sujeito não se debruçaria sobre o mundo para falar sobre fatos, mas para contemplar em silêncio um espaço lógico do qual o mundo seria apenas um recorte arbitrário, gratuito e imotivado. O mundo, deste ponto de vista, apareceria ao sujeito como uma presença bruta, uma possibilidade entre infinitas outras. Para este sujeito já não importaria determinar proposicionalmente como o mundo é, pois, ainda que ele fosse muito diferente do que é, o milagre dessa presença bruta seria exatamente o 
mesmo, e teria exatamente a mesma força. O sujeito do Tractatus, na sua dimensão mística, não discursiva, continua exercitando a intencionalidade que o define, mas não a usa para fazer apostas no tabuleiro da bipolaridade. Por trás do como contingente, ele divisa um que absolutamente necessário, e compreende (ou vê) que, à impossibilidade lógica de dizer o que quer que seja a respeito dessa presença, corresponde a obrigação ética de se calar. Esta é, a meu ver, a versão tractariana para o espanto diante de um ser que não se opõe a outros seres possíveis, mas ao nada absoluto em que não haveria nem este mundo possível, nem qualquer outro. Tanto o sujeito que contempla, quanto aquilo que é contemplado não devem ser tomados como um apêndice desvinculado do restante da obra. O que o sujeito contempla é o reino do sentido, e ele próprio é o sujeito que, na linguagem, visa esse mesmo reino sem se dar conta disso.

\section{VI}

No aforismo 5.631, Wittgenstein parece negar tudo o que foi dito até aqui: "O sujeito que pensa e representa", diz ele, "não existe". O que venho sustentando é que, pelo contrário, a linguagem exige um sujeito que institua relações de significação e realize operações lógicas. Este sujeito, exigido pela linguagem, poderia a justo título ser chamado de sujeito do pensamento, já que é graças a ele que os sentidos que pensamos chegam a se formar. Tentei mostrar ainda que este sujeito é também aquele capaz de contemplar o mundo do ponto de vista da eternidade, quando, ao invés de exercer sua intencionalidade para preencher o sentido dos nomes, ou inverter o sentido das proposições, faz com que ela se dirija diretamente, em silêncio, à ordem atemporal do espaço lógico, visando a totalidade do mundo como uma possibilidade entre muitas, ao invés de visar esta ou aquela contingência no interior do mundo. Ora, se não existe um sujeito do pensamento, se o pensamento não é de um sujeito, se ele é de ninguém, então não faz sentido derivar o sujeito transcendental dos mecanismos da linguagem. Neste caso, o que é dito na parte final do Tractatus terá mesmo que ser lido como um apêndice frouxamente ligado ao restante do livro, e talvez não haja nada de muito melhor a ser feito do que traçar cadeias de influências que nos 
levem a Schopenhauer, à mística alemã do final da Idade Média, ou (por que não?) a Parmênides, ou ao Zen Budismo, conforme já se fez.

Já afirmei que não existe nenhum aforismo do Tractatus que pudesse dar apoio à minha leitura. Em nenhum lugar Wittgenstein afirma com todas as letras, por exemplo, que a nomeação exige a atuação de um sujeito, muito menos de um sujeito visto como uma intencionalidade pura atuando nos limites do mundo. E mesmo quem aceita minha argumentação de que esse sujeito é, de fato, exigido pela economia interna do livro, não está obrigado a aceitar que o sujeito metafísico de que Wittgenstein fala ao final do livro tenha alguma coisa a ver com aquela intencionalidade pura ocupada em articular sentidos que estaria submersa nas partes iniciais do Tractatus. $\mathrm{O}$ que ninguém poderia negar, a meu ver, é o compromisso do Tractatus com a existência necessária de um sujeito metafísico. O aforismo 5.641 é uma solene e inequívoca declaração desse compromisso:

Assim, há realmente um sentido em que se pode, em filosofia, falar não psicologicamente do eu. O eu entra na filosofia pela via de que "o mundo é meu mundo". O eu filosófico não é o homem, não é o corpo humano, ou a alma humana, de que trata a psicologia, mas o sujeito metafisico, o limite - não uma parte - do mundo.

Este aforismo é a conclusão de uma longa série de observações na qual o aforismo que parece refutar minha leitura está inserido. Esta série de observações tem início com a constatação de que "eu sou meu mundo" (5.63). Antes de concluir, portanto, que Wittgenstein está afirmando que a linguagem não tem sujeito, ou que, mesmo exigindo um sujeito, este não tem nada a ver com o "eu filosófico" tão enfaticamente afirmado em 5.641, examinemos mais de perto esse grupo de aforismos e tentemos formular uma interpretação para eles.

Lembremos mais uma vez que "mundo" é um termo técnico no Tractatus. Mundo é "tudo que é o caso" (1), é a "totalidade dos fatos" (1.1), ou, mais precisamente, esta totalidade considerada contra o pano de fundo do espaço lógico (1.13). O espaço lógico é a totalidade das situações "dizíveis", das situações que podem ser representadas na linguagem. O mundo é uma parte dessa totalidade. Ele é constituído pelas situações possíveis correspondentes às proposições verdadeiras da linguagem. Ao 
afirmar que "o sujeito que pensa, representa, não existe", Wittgenstein não está dizendo que o sujeito que pensa e representa não seja um pressuposto necessário da linguagem. "Não existe", neste caso, quer dizer simplesmente "não está no mundo", não torna verdadeira nenhuma proposição em nenhum mundo possível. Dizer que o sujeito que pensa e representa "não existe" é, neste contexto, simplesmente dizer que ele não é um fato. Isto fica tão claro quando lemos a continuação do aforismo, que é difícil imaginar de que outro modo ele poderia ser interpretado. Citemos a mesma passagem, agora inserindo-a em seu contexto próprio:

Se eu escrevesse um livro O Mundo tal como o Encontro, nele teria que incluir também um relato sobre meu corpo, e dizer quais membros se submetem à minha vontade e quais não, etc. Este é bem um método para isolar o sujeito, ou melhor, para mostrar que, num sentido importante, não há sujeito algum: só dele não se poderia falar neste livro.

O final desta passagem contém uma paráfrase e uma glosa da afirmação que nos interessa. A afirmação de que "num sentido importante, não há sujeito algum", inserida no final do aforismo, só pode ser vista como uma forma de repetir a afirmação feita no início, de que "o sujeito que pensa, representa, não existe". O "sentido importante" no qual "não há sujeito algum" só pode ser aquele em que estamos falando, não do corpo humano, nem dos estados e processos mentais de alguém, mas sim do "sujeito que pensa e representa". O corpo humano existe, isto é, faz parte do mundo; estados e processos mentais também existem, fazem parte do mundo, podem ser descritos pela linguagem - podem ser pensados. $\mathrm{O}$ que Wittgenstein afirma que não existe é o sujeito do pensamento, e, ao afirmar que ele não existe, quer dizer apenas que ele não pode ser pensado. É só deste sujeito que não se poderia falar num livro que apresentasse uma descrição completa de minha vida. O corpo que escreveu o livro poderia ser descrito, e as ocorrências mentais que acompanharam a elaboração do livro, também. O verdadeiro autor do livro, porém, o sujeito que construiu os sentidos ali expressos, esse teria que ficar de fora.

É importante lembrar que esta descrição completa de minha vida, embora não contenha nada que diga respeito ao sujeito que pensou aquelas proposições, é, segundo vem dito no aforismo, "um método para isolar o sujeito". Pensando, e falando a respeito de tudo que pode ser dito, 
o sujeito não desaparece. Num sentido importante, ele ganha destaque. Ele se destaca exatamente como aquilo de que não foi possível falar. Se o sujeito que pensa e representa fosse para Wittgenstein um nada absoluto, sem lugar no mundo, mas sem lugar também nos limites do mundo, não teria sentido falar, aqui, num "método para isolá-lo", num método para colocá-lo em destaque. Não podemos falar do sujeito do pensamento e da linguagem - isto é uma outra coisa. Esse sujeito não pode ser descrito, não é um fato, e, neste sentido, não existe. Mas ele é sem dúvida algo que pode ser isolado como um pano de fundo do dizível, algo que pode ser posto em evidência, ou, para usar a imagem clássica do Tractatus, é algo que, por não poder ser dito, só pode ser mostrado. Longe de afirmar que a linguagem não tem sujeito, o que Wittgenstein está dizendo de modo escancarado neste aforismo é que não só existe - num outro sentido - o sujeito que pensa e que representa, como ele é também condição de possibilidade de todo pensamento e de toda representação. Por isso mesmo ele não pode "existir" no primeiro sentido - uma condição de possibilidade da representação de fatos não pode, ela própria, ser um fato, e não pode, por isso, ser representada de forma alguma.

É neste sentido que, na filosofia, podemos falar "não-psicologicamente" do eu. A filosofia, quando fala de um eu não psicológico, acerta sem querer. Se ela erra, não é por aquilo que ela disse, mas simplesmente por ter dito o que só poderia, a rigor, ser mostrado (5.62). Ao dizer que "o eu entra na filosofia pela via de que 'o mundo é meu mundo", Wittgenstein está usando a palavra "mundo" no sentido técnico que ressaltamos mais acima. A totalidade dos fatos é a totalidade das situações possíveis no espaço lógico que tornam verdadeiras as proposições da minha linguagem - a única, aliás, que eu poderia entender (5.62), pois eu sou a única fonte de sentido de qualquer sentença - seja das sentenças que saem da minha boca, seja daquelas que chegam aos meus ouvidos. Por isso, e não por qualquer razão de ordem epistemológica, o mundo só pode ser meu mundo: porque a linguagem que o descreve, e em relação à qual esse mundo se define, só pode ser a minha linguagem. Se eu não existisse em nenhum sentido, a linguagem não seria minha, nem o mundo seria meu. Mas não é assim que Wittgenstein pensava, conforme fica claro numa leitura minimamente atenta do Tractatus. O que meu texto fez, na primeira parte, foi simplesmente buscar razões, no interior do 
Tractatus, para essa postulação de um sujeito metafísico coordenado ao mundo que esse mesmo sujeito é chamado a descrever ou a contemplar.

Quando se admite isto, fica difícil não admitir o restante de minha leitura. A oposição entre uma "vontade portadora do ético" e uma "vontade fenomênica" (6.423) dificilmente pode ser desvinculada da discussão que acabamos de examinar, que opõe o meu corpo e minha vontade fenomênica àquele "sujeito que pensa e representa", que não está no mundo, que não pode ser descrito, mas é condição de possibilidade de toda descrição. A interpretação rigorosa desta "vontade portadora do ético" envolveria uma série de considerações que não farei aqui. Para meus propósitos bastará, creio, estabelecer duas teses bastante simples. Primeiramente, a tese de que essa vontade que é "portadora do ético" e que não é fenomênica deve ser associada ao "sujeito que pensa e representa" e que não está no mundo. Em segundo lugar, a tese de que essa vontade "portadora do ético" é uma intencionalidade transcendental que se dirige ao mundo, não para representá-lo, mas para contemplá-lo sub specie aeterni. Se o sujeito do pensamento é o sujeito da ética, e se a atividade própria desta vontade "portadora do ético" é visar o mundo sub specie aeterni, então a atividade própria do sujeito que pensa deve também ser vista como uma "vontade" que não se dirige a uma parte do mundo, mas à sua substância atemporal. É exatamente assim que descrevi, mais acima, o sujeito da linguagem.

\section{VII}

Que a vontade "portadora do ético" deva coincidir com o "sujeito que pensa e representa" é algo que pode ser estabelecido, antes de tudo, pelo caráter absolutamente impalatável das alternativas disponíveis. Negar esta coincidência seria postular uma transcendentalidade esquizofrênica, uma dupla de sujeitos transcendentais associados a mim, cada um deles fazendo algo distinto do que o outro faz. Um "eu" estaria incumbido de contemplar a eternidade, enquanto o outro seria especializado na produção de sentidos. Teríamos que atribuir ao Tractatus um solipsismo bifronte, e isso estaria distante não apenas da letra do texto de Wittgenstein, mas também de seu espírito. Se admitimos, como me parece necessário 
admitir, que a linguagem, tal como concebida no Tractatus, necessita de um sujeito produtor de sentidos, e que a vontade não fenomênica deve ser a vontade de um sujeito não fenomênico, então será difícil imaginar uma interpretação que não identifique estes sujeitos, assumindo que eles devem ser uma só coisa em diferentes atribuições.

Que a vontade portadora do ético não se dirige aos fatos do mundo que não seja vontade deste ou daquele fato - é algo que pode ser estabelecido sem problemas. Sem entrar aqui nos dificeis meandros do texto wittgensteiniano, parece claro que ele concebe essa vontade inefável como uma ação que não é satisfeita ou frustrada por eventos mundanos. O exercício dessa vontade parece acarretar recompensas e castigos "imanentes" (6.422), ao contrário da vontade fenomênica, permanentemente envolvida com fatos logicamente independentes dela mesma, por ser, ela mesma, um fato entre outros. Como todo fato no mundo é completamente acidental, se a vontade portadora do ético também fosse vontade de certos fatos, ela jamais poderia encontrar em seu próprio exercício uma recompensa, ou um castigo, conforme o caso. Resta, então, perguntar: esta vontade não fenomênica é vontade de que, afinal de contas? A que ela se dirige?

A única resposta viável, no contexto tractariano, parece ser o mundo sub specie aeterni, o mundo como totalidade limitada, a que Wittgenstein faz referência no aforismo 6.45 , imediatamente depois da tematização das duas vontades. A intuição do mundo como totalidade - e totalidade limitada - é aquilo que o Tractatus chama de "sentimento místico". Essa intuição, ou sentimento de uma totalidade limitada se opõe claramente a uma atenção ou vontade dirigida aos fatos. $\mathrm{O}$ místico não se dirige a nenhum fato do mundo, ou, na expressão de Wittgenstein, a ele não interessa como o mundo é.Ao místico, interessa a existência do mundo - de um mundo qualquer, não importa qual. O sentimento místico é o sentimento de que existe um mundo, por oposição ao nada, e não de que ocorrem tais fatos, por oposição a tais outros.

O sentimento de "um mundo, não importa qual" coincide de um modo intrigante com a atividade de nomeação. Na nomeação, eu associo nomes a objetos que carregam consigo uma teia de possibilidades e impossibilidades combinatórias. Ter em vista a totalidade dos objetos é ter em vista a totalidade das combinações possíveis de objetos, ou seja, o 
espaço lógico no interior do qual nosso pensamento pode se mover em suas atividades descritivas. Ao nomear, eu viso o espaço lógico das possibilidades combinatórias, sem me importar em saber quais dessas possibilidades se realizam ou não. De um certo ponto de vista, todas as possibilidades me interessam; de um outro ponto de vista, não estou interessado em nenhuma particularmente. Para nomear, o sujeito deve projetar os nomes sobre a substância atemporal de que um mundo, não importa qual, é feito. Se fizermos com que os nomes saiam de cena, restará uma intencionalidade pura, de um lado, e a substância do mundo ("um mundo, não importa qual") do outro. Não conheço nenhum modo melhor de conceber essa vontade não fenomênica de que Wittgenstein nos fala. Na leitura que proponho, ela é o sujeito do pensamento e da linguagem exercitando a mesma intencionalidade que está na origem da nomeação para estabelecer um contato silencioso com a eternidade.

\footnotetext{
${ }^{1}$ A versão inicial deste texto original foi apresentada no X Colóquio Ibero-Americano de Filosofia realizado na Universidade Federal da Bahia de 19 a 21 de outubro de 2005.

2 Em função disto, a expressão "sujeito transcendental” não ocorre em nenhum aforismo do Tractatus. O adjetivo "transcendental" aplica-se à lógica (em 6.13, onde lemos que a lógica é "uma imagem do mundo vista num espelho") e à ética (em 6.421, logo após afirmar que um valor absoluto, que tenha, ele próprio, valor, deve "estar fora do mundo"). Um sujeito da lógica, bem como um sujeito da ética, poderiam ser chamados, a justo título, de "transcendentais". Wittgenstein refere-se explicitamente a um "portador do ético" (6.423) a respeito do qual nada poderia ser dito. Tentarei mostrar que podemos também falar num "sujeito da lógica", que é "transcendental" no mesmo sentido e pelas mesmas razões. Trata-se, se estou certo, do mesmo sujeito, em diferentes atribuições.
}

\section{Referências bibliográficas}

CUTER, J.V.G. 1999. “p” dice p. Theoría, México, D.F., nº 8 9, p. 5160.

CUTER, J.V.G. 2004. A Ética do Tractatus. Analytica, Rio de Janeiro, vol. $7, n^{\circ} 3$, p. 2335 .

WITTGENSTEIN, L. 1998. Tractatus Logico-Philosophicus. São Paulo: Edusp. 